\title{
PROPOSAL OF A MODEL FOR STRENGTHENING SCIENTIFIC PRODUCTIVITY AT THE UNIVERSITY LEVEL
}

\author{
Dr. Jorge Daher Nader ${ }^{1}{ }^{凶}$, Dr. Amelia Patricia Panunzio ${ }^{2}$, Dr. Marlene Hernández \\ Navarro ${ }^{1}$ \\ ${ }_{1}^{1}$ Professor at the University of Guayaquil, Ecuador \\ 2 University of Zulia, Venezuela
}

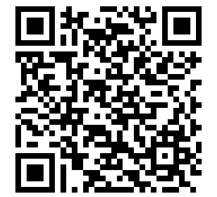

DOI: https://doi.org/10.29121/granthaalayah.v8.i9.2020.1677

Article Type: Research Article

Article Citation: Dr. Jorge Daher Nader, Dr. Amelia Patricia Panunzio, and Dr. Marlene Hernández Navarro. (2020). PROPOSAL OF A MODEL FOR STRENGTHENING SCIENTIFIC PRODUCTIVITY AT THE UNIVERSITY LEVEL. International Journal of Research -

GRANTHAALAYAH, 8(9), 415-421. https://doi.org/10.29121/granthaa layah.v8.i9.2020.1677

Received Date: 15 September 2020

Accepted Date: 30 September 2020

Keywords:

Research

Strengthening

Scientific Production

\section{ABSTRACT}

The proposal to strengthen scientific production at the university level has dimensions, components and characteristics and a structure designed based on the theoretical contributions of this research and the results obtained in each objective addressed, considering that scientific research is an indicator of the quality of the processes in the university environment, so it must be increased by virtue of the results of the work carried out by the research professors and students.

\section{INTRODUCTION}

Scientific production is an indicator of the quality of processes in the university environment, so it must be increased by virtue of the results of the work carried out by research teachers and students. A projective descriptive research is planned with the general objective of proposing a model for the strengthening of scientific production in the Faculty of Medical Sciences of the University of Guayaquil. The specific objectives that will allow the proposal will be, the characterization of the university management in research, the analysis of the scientific production in the period 2017-2019, the identification of the perception of the users regarding the scientific production, which together it will allow to establish the strategies to propose the strengthening model in this area. Theoretical and empirical methods will be used, within the former: deductive and within the latter: observation, interview, survey and questionnaire. The development of a model for the strengthening of scientific production within Research Management is proposed as a way to establish mechanisms for the dissemination of researchers' results. 
Proposal of A Model for Strengthening Scientific Productivity at The University Level

\section{METHODOLOGY}

This research work is of the following type: Projective: it consists in the elaboration of a proposal or a model, as a solution to a problem or practical need. (Hurtado. 2012)

Descriptive: a characterization of the research management of the FCM-UG will be carried out, the PC will be analyzed and the perception of teachers, students, authorities and graduates will be identified in relation to the aspects that could influence said indicator. (Hernández, 2014)

Quantitative: It serves as statistical tests that support the study of the problem through the analysis of data, which are collected in numerical quantities. . (Hernández, 2014)

TROUBLE: To measure the educational quality of a university, the key point is the process, that is, the phases and components of university activity and the elements that intervene in it; The result focuses on the mission and vision of said institution and is achieved in terms of training professionals, scientists; and advances in research and not less important, although more difficult to measure, the benefits obtained for society (Vallejo, 1992). In the CEAACES evaluation model, research is included as one of the most important processes within university management. An evaluation was carried out at the University of Guayaquil in 2013, being evaluated in category " $D$ ". The scientific production of the FCM was $2 \%$, it ranked last in all the criteria, and it did not meet the requirements for accreditation, due to the tiny percentage that was maintained. Low number of FCI Projects and Non-existence of research groups Lack of articulation of teaching, research and extension. Insufficient number of publications in regional and SCOPUS magazines. Insufficient training in research methodology and scientific writing. Lack of national and / or international inter-institutional networks. Scarce research funds in National and Regional calls Lack of scholarships and current research contracts

For the elaboration of the proposal of a model to raise the scientific production at the university level, the contribution obtained from the analysis and discussion of the results of each proposed objective was taken into consideration, as well as the theoretical postulates reviewed in the consulted bibliography. The methodological triangulation of the results of the applied instruments made it possible to define the arguments and the fundamental elements to take into account in the design of the model. The model taken as theoretical support in this research is the one proposed by Travieso (2012). This model includes three important elements that may be common to the model proposed in this research, they are: degree of contextualization of the analyzed problem, establishment of the relationships between the components that make up the model, and individual conceptions of the interwoven actors.

The proposal to strengthen the scientific production in the FCM-UG has dimensions, components and characteristics and a structure designed from the theoretical contributions of this research and the results obtained in each objective addressed.

Political dimension of the model: Research was not part of the study programs, in the eighties the CONUEP was created, a more popular conception of such institutions began to be created and, Therefore, a small percentage dedicated to research is established in the PGE, so that research activities are conceived as part of academic management in the country's HEIs, a situation that required, above all, a redirection of the policies and strategies outlined by the universities and polytechnic centers, as well as a transformation of the infrastructure according to the new demands. The impact of scientific research and technological development on the economic progress of countries is well recognized (King, 2004, Solarin and Yen, 2016). The study of scientific results in the form of publications is essential because it allows a diagnosis of institutional or national capacity (Inglesi-Lotz and Pouris, 2011; Pouris, 2012). This information is useful for decision-makers, who use it to design, adjust, generate and implement public policies aimed at increasing the production and quality of scientific research (Heitor et al, 2014). The little scientific research that is carried out in Ecuador is carried out in HEIs, in national research institutes financed with public funds, the government has promoted the increase of scientific production through the implementation of laws, improvements in universities, creation of scientific and technological transfer programs and the provision of funds to finance inter-institutional scientific research projects at the national and international level (Medina and others, 2016). Despite this, the UG being a public entity is influenced by the limited resources allocated to scientific research, through the VIGYP in which there is no established and systematic budget that supports the investigative processes. Scientific production in many cases is affected by this indicator. When analyzing the objectives of this research, the results were obtained that research management is becoming in recent years a topic of special relevance, both due to budget cuts and the growing demands for efficiency in research processes 
Methodological dimension of the Model: In accordance with the conceptual and theoretical bases of this research and the results obtained, this dimension focuses on establishing efficient research management in which its actors carry out a scientific activity that causes an improvement in scientific production in the FCM.

From the results obtained, it is evident that to develop an efficient university management, factors such as resources, processes and results must be taken into account that must be at the service and contribute positively to the development of teaching, research, and community service.

The teacher plays a very important role in the productivity and development of the research hotbeds, he must be able to build academic knowledge through research. Formative research coupled with research hotbeds promotes autonomous, creative learning, l. (Villalba Cuéllar JC and González Serrano A, 2018) Projects are a way to develop competencies in students as well as investigative skills such as: planning, organizing and carrying out a common task in real environments. Thus, they are organized into work teams, assume individual and group responsibilities, carry out inquiries or investigations, solve. (Arias Sandoval L, 2017).

Based on the analysis of the theoretical bases and the results obtained, the following pedagogical and methodological requirements are raised that support the proposal: (Dáher, 2020)

- Knowledge of teachers and students in research methodology and scientific writing

- Participation of teachers and students in research projects

- Existence of scientific societies

- Existence of research groups

- Distribution of financial resources for scientific research

- Formalization of spaces that promote scientific production from the curricular point of view, which continuously facilitate the progress of student learning

- Transfer of knowledge in the form of research reports, guidelines, or ways of action or solution.

\section{CHARACTERISTICS OF THE MODEL}

1) It has a systemic character, establishes the inter and intradependence of all its components to achieve the effectiveness of scientific activity. In a system all its elements must be ordered and integrated and work in a way that generates synergy, which means the result of teamwork where the elements interact with each other in order to achieve some objective. The result obtained is greater than if the result of each of the members is analyzed separately, (Domínguez Ríos, 2016)

2) It is comprehensive. The research activity is configured not only from the point of view of human resources, but also from the main lines of national, regional, local and university research, the various institutionalized forms of organization of the academic, scientific and technological space must be taken into account To carry out the research, the strategic vision of the research groups and intangible values such as material and financial resources, equipment and information (Jara, 2011) A component of the model alone does not achieve an effective result, its integration is required and systematic and organized synchronization.

3) Broad vision of material resources, essential to develop research as a quality object in the educational context, since it not only locates the analysis of the components of the research process, but also extends its conception to infrastructure, programs, study plans.

STRUCTURE OF THE MODEL: Based on these characteristics, the theoretical bases and the results obtained in the present investigation, necessary elements were considered to conceive an adequate functioning and relevance of the proposed model. Taking into account the analyzed theoretical provisions (related to research management, Oñate (2016) "individual and organizational knowledge." The first involves both knowledge and skills and attitudes, made up of knowledge itself and skills and the second is one that has been expressly converted into rules, procedures, strategies, resources, plans, programs and research projects, strategic alliances, models, scholarships, research groups, among others, it was determined that the components of the model are: personal and procedural.

Personal components: Based on the results that were obtained, a fundamental element in university scientific production is related to teachers and students as the main actors in the university community. When analyzing the perception of teachers and students, it was found that there are weaknesses in the development of capacities of students to present projects in instances of calls; few training related to project development, little participation in 
scientific dissemination events; little use of scientific articles by teachers in their chairs; as well as the need for greater emphasis on teaching the scientific method.

The analysis of the objective related to the perception of teachers and students allowed to corroborate that both have a great implication in the progress of research in the university, although they are formed, the processes correctly if teachers and students do not maintain a positive attitude towards the Scientific research would be of no use. Both components are essential for the execution of a quality scientific activity

However, it is conceived as novel in the proposal to see them in the same dimension from the point of view of how both should assume scientific research, of course the teacher always from his guiding function with greater knowledge and guidance of the students. It is about understanding the teacher and the student at the same level of involvement for the development of the scientific research process in the university from a more integrating edge of the phenomenon itself and in turn of each one separately. Both personal components presuppose elements that constitute common premises for scientific research such as: knowledge in research methodology and writing scientific articles, motivation towards scientific research, time available for this activity, participation in research projects, among others. In this sense, the preparation in research methodology of both is a significant indicator in the development of scientific production. (Daher, 2020)

Procedural components: According to Oñate (2016), the process is essential to achieve an optimal result. The process is specified in rules, procedures, strategies, resources, plans, programs and research projects, strategic alliances, scholarships, research groups, among others, which can be shared by the members of the organization.

According to the results obtained specifically in objective one where university management for research is characterized, for the indicators of each of the respective sub-dimensions: planning, execution and control and evaluation according to the opinion of the managers. It is shown that in the FCM there is operation of the rules that govern the investigation, although if they are established, there is bureaucracy in monitoring the processes investigative in the superior instances of the University. Rojas (2016) argues that in management by university processes, research plays a fundamental role if one takes into account that the humanistic and scientific progress of society depends on it. This must be pertinent and with a maximum pragmatic sense. It should be a permanent policy of the universities to develop an optimal investigative process based on the principles of ethics and humanism and that results in proposals that generate solutions to the social problems present in each context

By this category is understood what is related to the management of research processes, all the means, methods and procedures used in the taxable university. It should be taken into account: the academic actions that from the curricular and methodological level enhance and encourage research in teachers and students. These actions are framed in: designing study plans and programs where the research component is evidenced, either as part of the curriculum or as a cross-cutting axis to it, promoting the teaching pyramid by feeding the degree work with seed projects from the first years of the degree, apply the investigative method in classes, revitalize teaching with the use of scientific articles as a way to address the content.

The model reflects the close relationship between each of the components. They are shown as dependent entities for the advancement of scientific production at the university. None above another, but as a whole.

Within the procedural components are defined: project financing, scholarship management, operation of research groups, distribution of resources, existence of strategic alliances, and technological infrastructure. The harmonious, geared and integrating operation of all the components of the model in a single system, leads to an end that is to achieve quality higher education from research, teaching, and transfer of knowledge according to social needs

The interdependence between the components can also be valued from the following premises:

- The quality of the research depends among other factors on the quality of the preparation of teachers and students. (Criollo, and Fontaines, 2017)

- Students can become more and more empowered by research if teachers make it a daily practice in their classes. Castro, Sihuay and Pérez, 2016)

- A planned and systematic management will allow correcting in time the imperfections present in the research process (Oñate and Urdaneta, 2016,) and therefore strategies that facilitate the management of the research in the FCM can be drawn up.

The model is composed of the center (PC), a 1st circle (the 3 fundamental components that determine the PC according to the author's criteria are: teachers, students and research management), a 2nd circle (the elements of 
the model according to each component) and a 3rd circle (the end of the model). The different parts of the model are detailed below; For this we will start from the center towards the periphery.

In a 2nd circle the elements are represented according to the personal and procedural components of the model. In the case of teachers: knowledge of research methodology and scientific writing, participation in research groups, scientific societies and research projects.

The 3rd circle reflects three great university processes in which the research that they are is framed. Research itself, teaching and knowledge transfer, also known as knowledge management in connection with the community, all contribute to the continuous improvement of the quality processes of HEIs.

\section{Proposal of the model to strengthen scientific production at the university level}

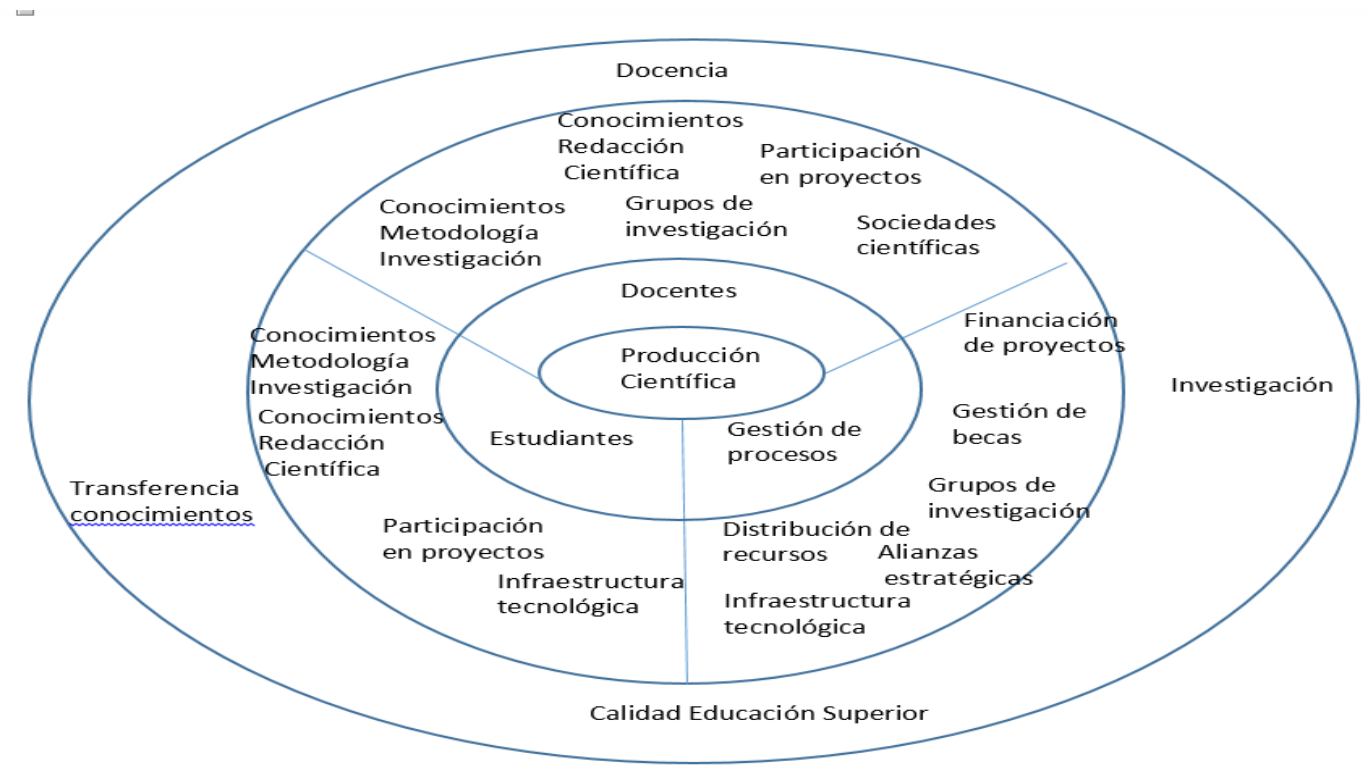

Made Daher, 2020

\section{RECOMMENDATIONS}

Based on the theoretical sources that have been systematized through this research and the results obtained in it, a series of recommendations are offered to the directors and academic body of the Faculty of Medical Sciences of the University of Guayaquil to improve scientific activity.

- Institutional support for research activities and maintaining a balance between its basic functions.

- Increase the preparation of teachers and students in research methodology and other related branches.

- Promote the formation of research groups at the intra and inter-institutional level.

- Join cooperation networks with other universities, organizations or institutions in the region and the country.

- Incorporate in the curriculum in a systematic way, activities that promote scientific research at the student level. Control your execution

- Update the lines of research according to social needs, fostering the faculty activities for the definition of lines, programs and research projects based on the development of knowledge and the demands of society

- Promote academic events of continuing education such as courses, congresses, panels, seminars, forums, workshops of inflection, reflection and intervention or other types of events that promote and tax academic exchange and stimulate the training of teachers and students.

- Promote postgraduate studies (specialties, masters and doctorates) with scholarships managed by the Ministry of Public Health MSP. to the Ecuadorian Institute of Social Security IESS, to the National Secretary of Higher Education, Science and Technology SENECYT, etc. or self-financed based on 
institutional research lines as a way to obtain financial resources to strengthen the infrastructure and technological equipment of the laboratories, especially the Centers of Excellence of the Faculty of Medical Sciences of the University of Guayaquil.

- Manage external financial support for the training of human resources and the carrying out of research activities.

- Incorporate research activities into the university curriculum and in turn carry out actions to control compliance.

- Formulate research projects related to teaching according to the needs detected.

- Encourage students' degree work to pay tribute to research projects and obviously to research lines.

- Encourage outstanding teachers and students in research.

\section{SOURCES OF FUNDING}

This research received no specific grant from any funding agency in the public, commercial, or not-for-profit sectors.

\section{CONFLICT OF INTEREST}

The author have declared that no competing interests exist.

\section{ACKNOWLEDGMENT}

None.

\section{REFERENCES}

[1] Ayala E. Scientific research in Ecuadorian universities. Annals. 2015; 3 (57): 61-72.

[2] Rojas A. Quality assurance and its contribution to the development of the University of Talca. In: International Seminar on Quality in Higher Education. May 11 2016. Montevideo: Catholic University of Uruguay; 2016. p.132.

[3] Wong LN. Teacher perceptions and organizational conditions to implement a research culture among university faculty. The case of UCSG [thesis]. Ecuador: University of Almería; 2015.-Gonzales-Saldaña J, Chavez-Uceda T, Lemus-Arteaga K, I, Galvez-Olortegui T, Galvez-Olortegui J. Scientific production of the Faculty of Medicine of the Peruvian university in SCOPUS and Pubmed. Educ Med [2017 16 Feb 2018]; -Narro Robles J. Challenges of the university in the XXI century. Rev Iberoam de Educ Super [Internet]. 2014 [cited 18 Mar 2018

[4] Bascó, Barbón, Solís, Poalasín and Pailiacho. (2017). Diagnosis of student scienti fi c activity in Medicine at the National University of Chimborazo. Educ Med. 18 (3): 154 --- 159

[5] Baron, Robert and Byrne and Donn. (2005). Social psychology. Mexico: Pearson. Prentice Hall. Spain. Madrid

[6] Bordons, Zulueta (1999). Evaluation of scientific activity through bibliometric indicators RevEspCardiol.; 52: 790-800 - Vol. 52 No. 10.

[7] Ceballos, Cantarero, Pascual, (2004). The Bologna treaty and higher education: A comparative experience of introduction of ICTs in economics. Barcelona: Edutec.

[8] National Council for the Evaluation and Accreditation of Higher Education. (2009). Institutional performance evaluation of the universities and polytechnic schools of Ecuador. Quito: CONEA. Retrieved from http://www.ceaaces.gob.ec/sitio/wp-content/ uploads / 2014/02 / INFORME_FINAL_UNIVERSIDADES_M141.pdf

[9] De las Salas, (2014). Attitude of the university student towards research in the Luz nucleus - Eastern Coast of the Lake Legal Deposit: PPI200802ZU2980 / ISSN: 1856-9331. Edition No 18 - Year 9 - October 2014 - March 2015.

[10] Diez de Castro, (2001). Administration and Direction. Editorial Mc Graw Hill. Interamericana de España Garrido, (2001) Bibliometric analysis of scientific productivity in the MAPFRE MEDICINA journal. FREMAP International Journal of Research -GRANTHAALAYAH 
Madrid II Assistance Center of the Sánchez F. 2 Gala. Mapfre Medicina, 2001; 12: 157-167 Jiménez, Terriquez, Robles, (2011).

[11] Evaluation of the academic satisfaction of the students of the Autonomous University of Nayarit. Revista Fuente, 2 (6), 46-56 López, (2014). Quality management models. European Model of Excellence. Spain: Colegio Sagrado Corazón Jesuitas León. Available at: http://www.jesuitasleon.es/calidad/Modelos\%20de\%20gestion\% 20de\% 20calidad.pdfMantilla, (2007)

[12] Research management: differentiations and relationships. Available at: http://revistas.usta.edu.co/index.php/hallazgos/article/viewFile/1668/1817Molero, Contreras, Casanova, (2016). Knowledge management as a tool for research productivity in the university sector. Legal Deposit: PPI200802ZU2980 / ISSN: 1856-9331. Edition No 21 Muñoz, (2000).

[13] Towards an intercultural education: Approaches and Models. Complutense University of Madrid: Education meetings. 1 , 81-106.D Dipsonible at: http://qspace.library.queensu.ca/bitstream/1974/628/1/sedano.pdfPezántez, (2011).

[14] Management and quality indicators of Higher Education. Master in Integrated Quality, Environment and Safety Management Systems. SaleRodríguez Polytechnic University, Castañeda, (2001). Teachers in research and innovation contexts. In Revista Iberoamericana de Educación, 25, 103-146. 